\title{
Correction to: A Semantic Framework to Support AI System Accountability and Audit
}

Iman Naja, Milan Markovic, Peter Edwards, and Caitlin Cottrill

\author{
Correction to: \\ Chapter "A Semantic Framework to Support AI System \\ Accountability and Audit" in: R. Verborgh et al. (Eds.): \\ The Semantic Web, LNCS 12731, \\ https://doi.org/10.1007/978-3-030-77385-4_10
}

In the original version of this chapter, figure 3 was incorrect. This has been updated in the chapter as seen below.
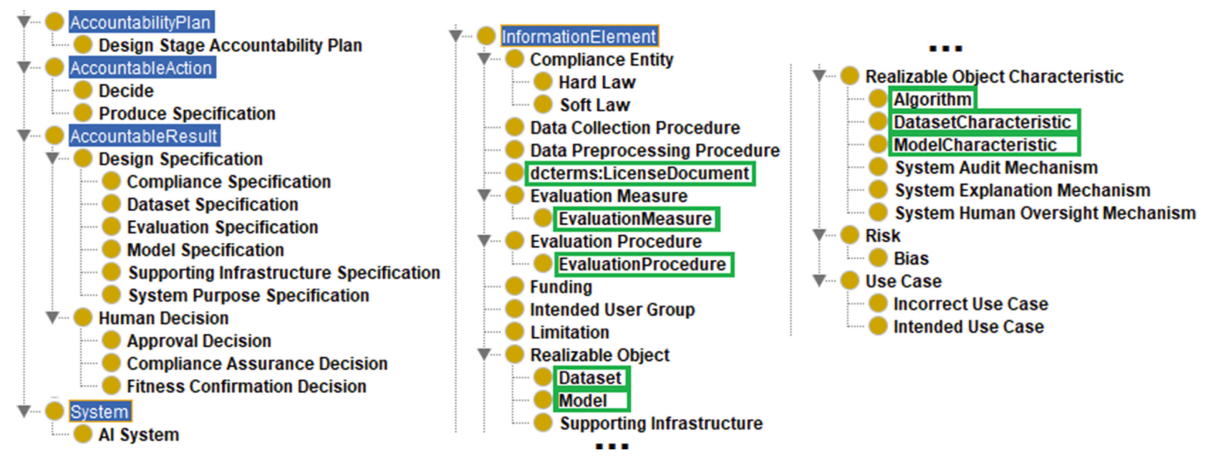

Fig. 3. RAInS classes as subclasses of SAO classes (in blue-filled rectangles). Third party classes reused from ML Schema and Dublin Core vocabulary have green borders. (Color figure online)

The updated version of this chapter can be found at https://doi.org/10.1007/978-3-030-77385-4_10 